\title{
The Possible Interplay of Synaptic and Clock Genes in Autism Spectrum Disorders
}

\author{
T. BOURGERON \\ Human Genetics and Cognitive Functions Unit, Department of Neuroscience, Institut Pasteur, \\ Paris, France, and Université Denis Diderot Paris 7, Paris, France
}

\begin{abstract}
Autism spectrum disorders (ASD) are complex neurodevelopmental conditions characterized by deficits in social communication, absence or delay in language, and stereotyped and repetitive behaviors. Results from genetic studies reveal one pathway associated with susceptibility to ASD, which includes the synaptic cell adhesion molecules NLGN3, NLGN4, and NRXN1 and a postsynaptic scaffolding protein SHANK3. This protein complex is crucial for the maintenance of functional synapses as well as the adequate balance between neuronal excitation and inhibition. Among the factors that could modulate this pathway are the genes controlling circadian rhythms. Indeed, sleep disorders and low melatonin levels are frequently observed in ASD. In this context, an alteration of both this synaptic pathway and the setting of the clock would greatly increase the risk of ASD. In this chapter, I report genetic and neurobiological findings that highlight the major role of synaptic and clock genes in the susceptibility to ASD. On the basis of these lines of evidence, I propose that future studies of ASD should investigate the circadian modulation of synaptic function as a focus for functional analyses and the development of new therapeutic strategies.
\end{abstract}

\section{INTRODUCTION}

As a result of a highly complex phylogenetic and ontogenic process, humans have acquired the ability to communicate with language and highly specialized skills to recognize social cues (eye gaze, joint attention, theory of mind, empathy). In some individuals, this ability to communicate is hampered by the occurrence of genetic/epigenetic variations and/or environmental insults. After exclusion of known biological diseases (e.g., deafness) and known environmental causes (e.g., social and teaching), approximately $8-10 \%$ of school age children suffer from language and/or communication difficulties (Shaywitz et al. 1990; Fombonne 2005). One of the most severe syndromes associated with an alteration of language and social communication is autism.

Autism was first described by the psychiatrist Leo Kanner in 1943 and is diagnosed on the basis of three behaviorally altered domains, namely, social deficits, impaired language and communication, and stereotyped and repetitive behaviors (Kanner 1943). Beyond this unifying definition lies an extreme degree of clinical heterogeneity, ranging from debilitating impairments to mild personality traits. Hence, autism is not a single disease entity, but rather a complex phenotype encompassing either multiple "autistic disorders" or a continuum of autistic-like traits and behaviors. To take into account this heterogeneity, the term autism spectrum disorders (ASD) is now used and includes autistic syndrome, pervasive development disorder not otherwise specified (PDD-NOS), Asperger syndrome, childhood disintegrative disorder (CDD), and Rett syndrome (APA 1994). Whereas CDD and Rett syndrome are severe neurological disorders, Asperger syndrome refers to the portion of the ASD continuum characterized by higher cognitive abilities and by more normal language function.
The behavioral singularities that occur in ASD are related to a wide spectrum of cognitive functions such as language, memory, and visual and auditive attentions. Two of these cognitive deficits are rather characteristic of ASD: a weak "central coherence" and the lack of a "theory of mind." "Central coherence" defines our ability to understand context. Individuals with ASD are sometimes better than age-matched controls in detecting details in a picture, but they have great difficulty in seeing "the bigger picture" and in understanding the context of the situation (Frith 1998). The term "theory of mind" describes an individual's understanding of the motives, knowledge, and beliefs of others. Individuals with ASD have an absence of theory of mind or a delay in the acquisition of it. This deficit could be a major cause of their difficulties in social interactions (Baron-Cohen et al. 1985).

Epidemiologic studies report a dramatic rise of ASD during the last two decades (from 2-5 to 60/10,000 children). However, this recent increase is most likely explained by the use of broader diagnostic criteria and the increased attention by the medical community (Fombonne 2005). For still unknown reasons, males are more frequently affected than females. The male-tofemale ratio is $4: 1$, but it increases to $23: 1$ in individuals without identified morphological or brain abnormalities.

\section{GENETIC CAUSES OF AUTISM SPECTRUM DISORDERS}

Since the original reports by Kanner and Asperger, many studies have advocated a genetic etiology for autism (Freitag 2007). Familial cases are substantially more frequent than expected by chance. Hence, the recurrence risk of autism in sibships is approximately 45 times greater than in the general population. Furthermore, twin studies have documented a higher concordance rate in 
monozygotic (60-91\%) than in dizygotic twins (0-6\%) (Bailey et al. 1995). However, due to the heterogeneity of the syndrome and the absence of apparent mendelian segregation, the mode of inheritance of ASD is still a matter of debate.

The long-time postulated polygenic model was recently challenged by the identification of rare cases of an apparently monogenic form of ASD caused by a single-gene mutation or de novo copy-number variants (CNVs) (Jamain et al. 2003; Jacquemont et al. 2006; Durand et al. 2007; Sebat et al. 2007, Szatmari et al. 2007). Although currently restricted to a limited number of patients, these apparent monogenic forms of ASD may be more frequent than originally expected. In addition, epigenetic anomalies are strongly suspected, but their actual impact on autism remains largely unknown.

In approximately $30 \%$ of the cases, ASD are associated with a known genetic syndrome or with chromosomal rearrangements (Fig. 1) (Freitag 2007). The association with known genetic disorders indicates that anomalies in distinct physiological processes such as chromatin remodeling (Rett syndrome; MECP2), synaptic gene regulation (Fragile-X syndrome, FMRP), protein synthesis and actin cytoskeleton dynamics (tuberous sclerosis, TSC1/TSC2; neurofibromatosis NF1), cell growth (Cowden syndrome, PTEN), and calcium signaling (Timothy syndrome, CACNA1C) can increase the risk for an individual to have ASD. However, if the causative genes are numerous and diverse, they might all interfere with a more restricted number of downstream pathways at the origin of ASD. Consistent with this hypothesis, several synaptic genes were found to be strongly associated
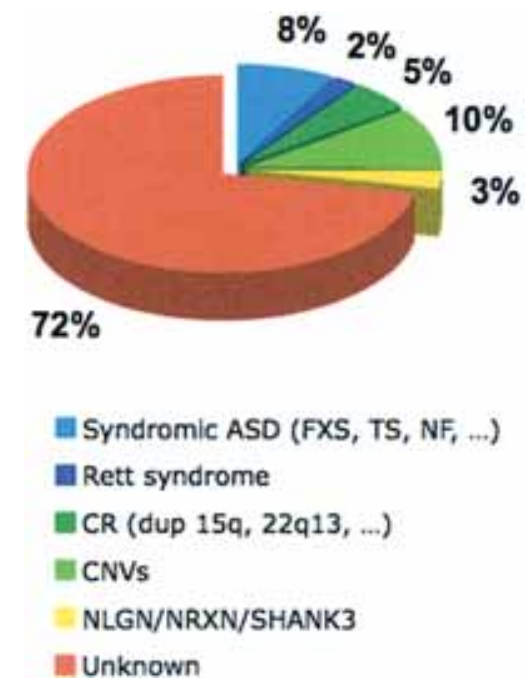

Figure 1. Broad estimation of the heterogeneous causes of ASD. ASD includes about $8 \%$ of known genetic syndromes (e.g., Fragile-X syndrome [FXS], tuberous sclerosis [TS], neurofibromatosis $[\mathrm{NF}]$ ), about $2 \%$ of Rett syndrome, about $5 \%$ of chromosomal rearrangements (CR), about $10 \%$ of copy-number variants (CNVs), about 3\% of mutations in the NLGN/NRXN/ SHANK3 pathway, and about $72 \%$ of unknown causes. These numbers are only a broad estimation because epidemiological data concerning the causes of ASD are missing. In addition, the percentage may vary for sporadic or familial cases and if the affected individual has dysmorphic features. with nonsyndromic ASD, providing a better view of the complex pathways, which alter properties of the neuronal networks and likely contribute to the disorders (Belmonte and Bourgeron 2006).

\section{SYNAPSES AND AUTISM \\ SPECTRUM DISORDERS}

\section{Synaptic Genes and Autism Spectrum Disorders}

The first synaptic genes associated with autism and Asperger syndrome to be discovered were the X-linked neuroligins $N L G N 3$ and NLGN4. Neuroligins are cell adhesion molecules with an esterase domain that have a crucial role in the formation of functional synapses. They are located at the postsynaptic side of the synapse and bind to other cell adhesion molecules called neurexins located on the presynaptic side of the synapse (Fig. 2). There are five neuroligin genes, NLGN1, NLGN2, $N L G N 3, N L G N 4$, and NLGN4Y, in the human genome. Searching for mutations in X-linked genes, Jamain et al. (2003) identified a frame-shift mutation in the NLGN4 gene in two brothers, one with autism and the other with Asperger syndrome (Jamain et al. 2003). This mutation

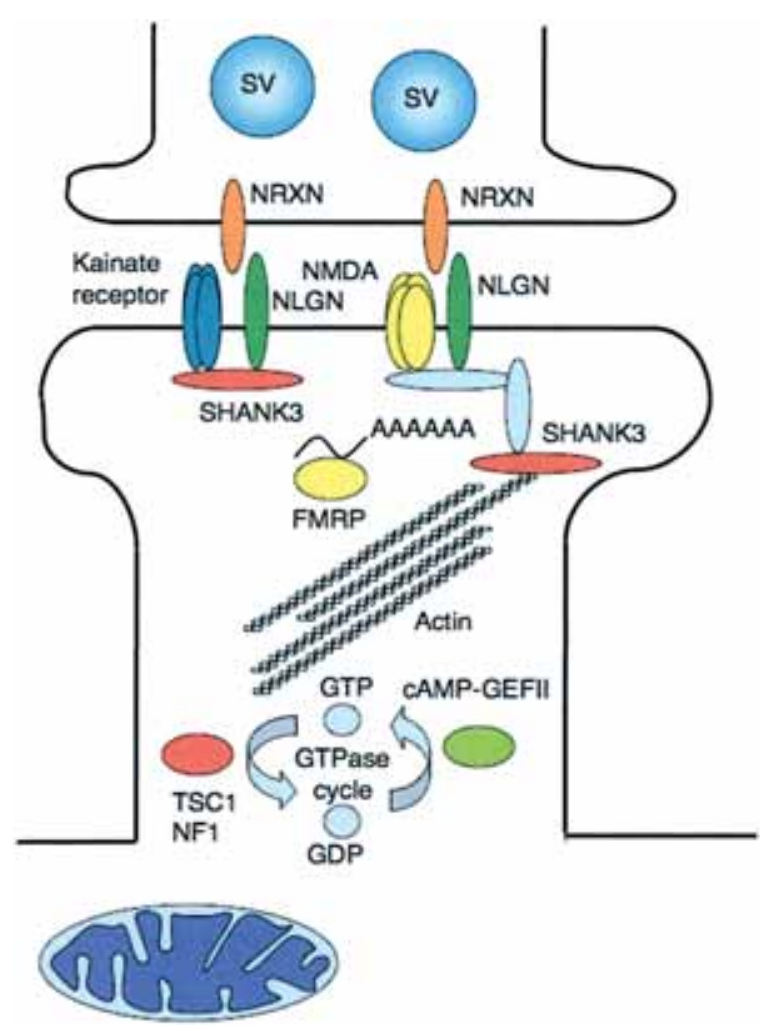

Figure 2. Synaptic genes associated with ASD. Synaptic vesicles (SV) and neurexins (NRXN) are present at the presynaptic side of a glutamatergic synapse. At the postsynaptic side, the NLGN and the glutamate receptors bind to scaffolding proteins of the postsynaptic density (PSD) such as SHANK3. FMRP controls the translation of several synaptic proteins. TSC1 and NF1 are regulating the actin dynamics and the morphology of the neuron. MECP2 (not shown here) regulates gene expression by modifying chromatin structure. 
(D396X) was located in the esterase domain, leading to premature termination of the protein before the transmembrane domain. In the same study, a nonsynonymous mutation (R451C) of the X-linked NLGN3, which affects a highly conserved amino acid from the esterase domain, was identified in a second family with two brothers, one with autism and one with Asperger syndrome. These mutations (NLGN4 D396X and NLGN3 R451C) were intensively studied at the functional level and were found to cause abnormal synaptogenesis in cultured neuronal cells (Chih et al. 2004; Comoletti et al. 2004). Although mutations in NLGN3- and NLGN4-coding sequences are rare in individuals with ASD $(<1 \%$ of the individuals) (Vincent et al. 2004; Blasi et al. 2006), other groups have identified independent NLGN4 mutations in individuals with ASD and/or mental retardation (Laumonnier et al. 2004; Yan et al. 2005). In addition, abnormal NLGN3 and NLGN4 spliced isoforms were detected in blood cells from individuals with ASD (Talebizadeh et al. 2006). If these abnormal transcripts are actually present in the brain of the affected individuals, this finding may represent a new type of $N L G N$ alteration in ASD.

The second gene identified within this pathway was SHANK3 located on chromosome 22, a region deleted in several individuals with ASD (Manning et al. 2004). SHANK3 is a scaffolding protein of the postsynaptic density (PSD), which binds to the NLGN, and known to regulate the structural organization of dendritic spines (Boeckers et al. 2002; Meyer et al. 2004). Durand et al. (2007) sequenced the coding sequence of SHANK3 in 227 individuals with ASD and showed that mutations, or loss of one copy of the gene, are associated with autism, whereas the presence of an extra copy might be associated with Asperger syndrome. Among the variations identified, a de novo frame-shift mutation that originated in a mother with germinal mosaicism was present in two brothers with autism. Expression in cultured neurons of the rat Shank3 cDNA carrying the frame-shift mutation indicated that the truncated protein, in contrast to the fulllength protein, is absent in the dendritic spines. These results provided further genetic and functional evidence that the synaptic pathway, which includes $N L G N, N R X N$, and SHANK3, is associated with ASD.

Finally, the third gene identified within this pathway is $N R X N 1$ on chromosome $2 \mathrm{p}$. Using a whole-genome approach, an international collaborative effort-the Autism Genome Project Consortium-investigated 1168 multiplex families for the presence of linkage and CNVs (Szatmari et al. 2007). This analysis detected a new locus for autism on chromosome 11 and the presence of a de novo deletion of the NRXN1 gene located on chromosome 2 p16 in two sisters with ASD. The NRXN1 gene encodes neurexin, the presynaptic partner of the $N L G N$, confirming that a defect in this synaptic pathway could cause ASD.

Other synaptic genes may be associated with ASD (Persico and Bourgeron 2006). Three of these candidate genes encode glutamate receptor subunits, the glutamate receptor ionotropic kainate 2 gene (GRIK2 or GluR6) (Jamain et al. 2002), the $N$-methyl-D-aspartate (NMDA) receptor-2 subunit (GRIN2A) (Barnby et al. 2005), and glutamate receptor ionotropic AMPA 3 (GRIA3) (Jacque- mont et al. 2006). These proteins are direct (or close) binding partners of the NLGN/NRXN1/SHANK3 protein complex, but the functional consequence of the "risk alleles" remains largely unknown.

\section{Atypical Synapses in Autism Spectrum Disorders?}

Taken together, these results strongly suggest that the NRXN/NLGN/SHANK protein complex has an important function in ASD. Although little data exists on the specific role of this pathway in the human brain, studies on neuronal cell culture and animal models provided crucial information on its function.

First, neuroligins and neurexins enhance synapse formation in vitro (Scheiffele et al. 2000) but, surprisingly, are not required for the generation of synapses in vivo (Varoqueaux et al. 2006). Indeed, results from knockout (KO) mice demonstrate that neither NLGNs nor neurexins are required for the initial formation of synapses, but both are essential for synaptic function and mouse survival (Missler 2003; Varoqueaux et al. 2006). Therefore, neuroligins may not establish but may specify and validate synapses via an activity-dependent mechanism, with different neuroligins acting on distinct types of synapses (Chubykin et al. 2007). This model, proposed by Chubykin et al. (2007), reconciles the overexpression and knockout phenotypes and suggests that neuroligins contribute to the activity-dependent formation of neural circuits.

Second, neuroligins and neurexins are also emerging as central organizing molecules for excitatory glutamatergic and inhibitory GABAergic synapses in mammalian brain (Graf et al. 2004; Prange et al. 2004). NLGN1, NLGN3 and NLGN4 are specific to glutamatergic synapses, whereas NLGN2 is restricted to GABAergic synapses (Varoqueaux et al. 2004). A selectivity for glutamatergic versus GABAergic synapse is also conferred by alternative splicing of both partners (Craig and Kang 2007). An insertion of an alternatively spliced exon in $\beta$-neurexins selectively promotes GABAergic synaptic function, whereas an insertion of an alternative spliced exon in neuroligin 1 selectively promotes glutamatergic synaptic function. This role in synaptic specificity is highly relevant to ASD because imbalance between excitation and inhibition could lead to epilepsy, a disease observed in almost $25 \%$ of individuals with ASD (Freitag 2007).

Finally, at least in humans, this pathway appears to be highly sensitive to gene dosage. Indeed, a deletion of a single copy of SHANK3 or NRXN1 seems to be sufficient to cause ASD (Durand et al. 2007; Szatmari et al. 2007). Although the change in the number and/or the quality of the synaptic contacts may be subtle, the consequences at the cognitive level are obvious because patients sometimes present with complete absence of speech. This genedosage sensitivity of the complex is an important feature that should be taken into account when reconsidering the mode of inheritance of ASD and, more generally, for understanding the evolution of higher brain functions.

Taken together, these results indicate that the NLGN/NRXN/SHANK3 complex is actually associated with ASD. Nevertheless, it was shown that the severity of the syndrome associated with mutations within this path- 
way could greatly differ from one individual to another (even if they carry identical or similar mutations) (Jamain et al. 2003; Laumonnier et al. 2004). This relative heterogeneity in the phenotype indicates that this pathway could be modulated by other genetics and/or environmental factors. Among these factors, I propose that abnormal circadian rhythms may increase the risk as well as the severity of the disorder.

\section{Circadian Rhythms and Autism Spectrum Disorders}

Despite the fact that sleep is one of the major concerns for families having a child with ASD, this problem was often considered as an epiphenomenon and therefore did not catch the attention of the scientific community. However, recent results showing abnormal melatonin synthesis, as well as an efficacy of melatonin therapy for sleep problems observed in ASD, may change this initial disregard from a possible key role of the clock and circadian regulations in ASD.

\section{Clock Genes and Autism Spectrum Disorders}

The involvement of clock genes in ASD was first proposed by Wimpory et al. (2002). To test this hypothesis, Nicholas et al. (2007) screened single-nucleotide polymorphisms (SNPs) in 11 clock/clock-related genes in 110 individuals with ASD and their parents. A significant allelic association was detected for PER1 and NPAS2. Haplotype analysis within $P E R 1$ gave a single significant result $(P=0.03)$, whereas for NPAS2, 40 of the 136 possible two-marker combinations were significant at the $P$ $<0.05$ level, with the best result between markers rs1811399 and rs2117714 $(P=0.001)$. This first study of clock genes in ASD is promising, but the relatively small sample studied and the absence of significance after correction for multiple testing warrant the extension of these studies to larger cohorts.

The most consistent results reporting abnormal circadian rhythms in ASD concern the melatonin synthesis pathway. Melatonin is considered to be the hormonal message for darkness because it is released during the night in all vertebrates examined, independent of whether the animal is diurnally or nocturnally active. It is produced mainly in the pineal gland by the conversion of serotonin to $N$-acetylserotonin (NAS) by the rate-limiting enzyme AA-NAT (arylalkylamine $N$-acetyltransferase), followed by the conversion of NAS to melatonin by HIOMT (hydroxyindole $O$-methyltransferase) (Fig. 3, top) (Axelrod 1974). At least five independent groups detected abnormal melatonin levels in ASD (Rivto et al. 1993; Nir et al. 1995; Kulman et al. 2000; Tordjman et al. 2005; Melke et al. 2007). With the exception of Ritvo et al. (1993), who reported increased daytime urinary melatonin levels and similar nocturnal values, all of the remaining studies found an abnormal decrease of melatonin concentration in individuals with ASD.

Nir et al. (1995) observed an abnormal circadian pattern of melatonin in a group of 10 young adult males with ASD. Although not out of phase, the serum melatonin lev-
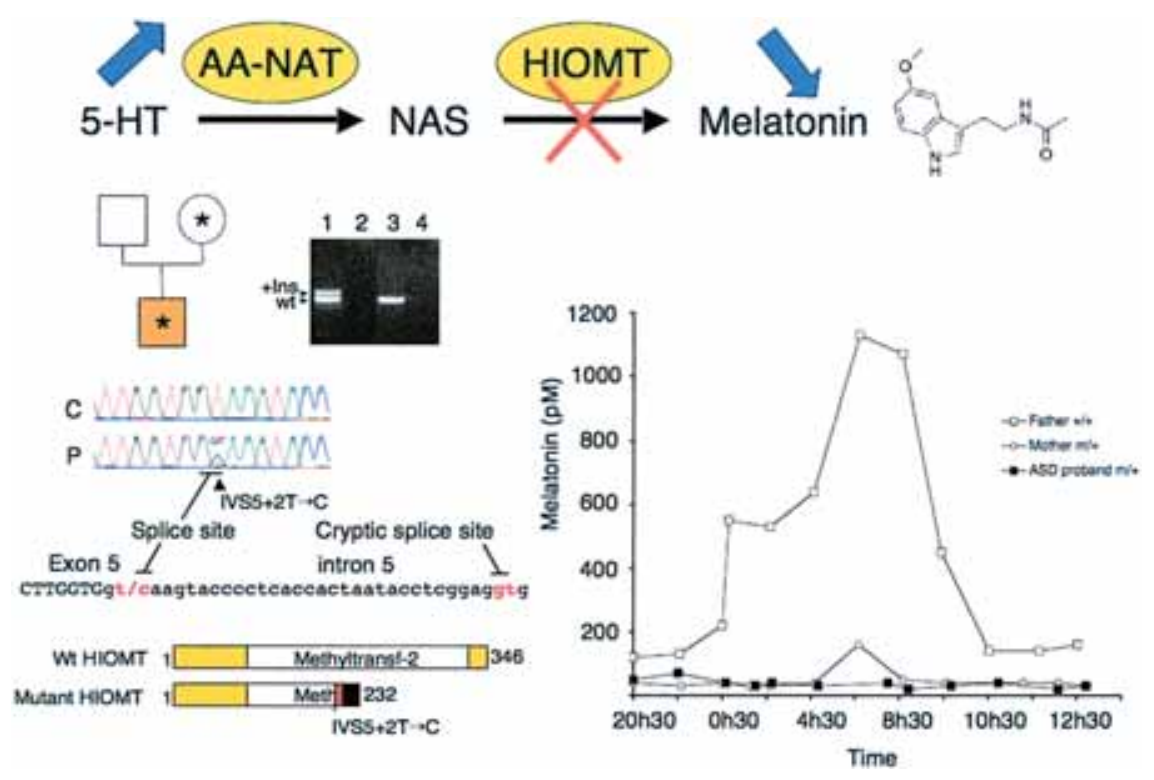

Figure 3. Abnormal melatonin synthesis in ASD. (Top) Melatonin is produced by the conversion of serotonin to $N$-acetylserotonin by the rate-limiting enzyme AA-NAT, followed by the conversion of $N$-acetylserotonin (NAS) to melatonin by HIOMT. A single deficiency of HIOMT may be responsible for the low melatonin level and the accumulation of serotonin observed in children with ASD. (Bottom left) Pedigree structure of a family carrying the splice site mutation IVS5 $+2 \mathrm{~T}>\mathrm{C}$. (Orange) Child with high-functioning autism. Reverse transcriptase-polymerase chain reaction (RT-PCR)-amplifying exons 4 to 6 of the ASMT cDNA from BLCL of the ASD1 proband carry the splice site mutation IVS5 + 2T > C (lane 1+RT; lane $2-\mathrm{RT}$ ) and a control (lane $3+\mathrm{RT}$; lane $4-\mathrm{RT}$ ). The insertion (+Ins) of $31 \mathrm{bp}$ in the $A S M T$ transcript should lead to premature truncation of the protein, lacking the methyltransferase domain. (Wt) Wild type. (Bottom right) Nocturnal melatonin profile of the proband (male, 24 years old), his mother (53 years old), and his father $(55$ years old). The proband $(\mathrm{P})$ and the mother $(\mathrm{M})$ are heterozygous $(\mathrm{m} /+)$ for the splice site mutation IVS5 $+2 \mathrm{~T}>\mathrm{C}$. The father does not carry the ASMT mutation (+/+). (Adapted from Melke et al. 2007.) 
els differed from normal in amplitude and concentration. Marginal changes in diurnal rhythms of serum thyroidstimulating hormone (TSH) and possibly prolactin were also recorded. Subjects with seizures tended to have an abnormal pattern of melatonin that correlated with electroencephalogram (EEG) changes.

Kulman et al. (2000) investigated 14 children with ASD and 20 age-matched controls for their whole 24hour circadian rhythms by collecting venous blood samples at 4-hour intervals. In their cohort, no autistic children showed a normal circadian rhythm. In more detail, 10 of 14 showed no daily variation in melatonin blood levels, whereas the remaining 4 patients had higher levels of melatonin during the day rather than during the night. The children with inverted circadian rhythms of melatonin may have had a disorder similar to Smith-Magenis syndrome (SMS). Indeed, patients with SMS present with inverted melatonin circadian rhythms and severe behavior problems similar to autism (De Leersnyder 2006). In this study, melatonin ( $5 \mathrm{mg}$ /day orally in the evening) was found to improve the sleep disturbance in two of three patients with a more pronounced disorder.

Tordjman et al. (2005) measured the overnight urinary output of the predominant melatonin metabolite, 6-sulphatoxymelatonin (6-SM) in the urine of 49 individuals with ASD and 88 controls. The nocturnal urinary excretion of 6-SM was significantly reduced in patients with ASD compared to controls (mean \pm S.E.M., $0.75 \pm 0.11$ vs. $1.8 \pm 0.17 \mathrm{~g} / \mathrm{hr}, P=0.0001)$. A large proportion of the individuals with autistic disorder ( 31 of $49,63 \%$ ) had 6SM excretion values that were less than half of the mean excretion rate observed in the control group. Furthermore, the low level of melatonin was correlated with the severity of autistic impairments in verbal communication and play $(p<0.05)$.

Taken together, these studies performed on different cohorts and using different methodologies indicate that an abnormal melatonin level is a frequent trait in ASD. Nevertheless, both the underlying cause of this anomaly and its relationship with ASD (cause or consequence?) were still unexplained. This dilemma was partly resolved by Melke et al. (2007), who used a combination of genetics and biochemical approaches to address these issues. The original aim of this study was to identify susceptibility genes for ASD on the pseudo-autosomal region 1 (PAR1). PAR1 is a short region of $2.7 \mathrm{Mb}$ located on both the $\mathrm{X}$ and $\mathrm{Y}$ chromosomes and deleted in several individuals with ASD. Among the 12 PAR1 genes, ASMT was considered to be an excellent candidate because it encodes HIOMT, the last enzyme in the melatonin biosynthesis pathway (Simonneaux and Ribelayga 2003). All ASMT exons and promoters were sequenced in 250 individuals with ASD. Variations affecting the protein sequence of HIOMT (N17K, K81E, G306A, and L326F) were enriched in the ASD group, and a splicing mutation (IVS5 $+2 \mathrm{~T}>\mathrm{C}$ ) was present in two families with ASD, but not in controls (Fig. 3, bottom left). In addition, two polymorphisms (rs4446909 and rs5989681) located in the promoter were more frequent in ASD compared to controls $(P$ $=0.0006)$ and were associated with a decrease in ASMT transcripts in B-lymphoblastoid cell lines $\left(P=2 \times 10^{-10}\right)$. Biochemical analyses performed on blood platelets of 43 individuals with ASD and 48 controls revealed a highly significant decrease in HIOMT activity $\left(P=2 \times 10^{-12}\right)$ and melatonin level $\left(P=3 \times 10^{-11}\right)$ in ASD. The HIOMT deficit was also detected in cultured cells of the patients, ruling out inhibitory effects of environmental factors or regulation acting at a higher physiological level.

All together, these results confirm that a large percentage of patients $(65 \%)$ have less than half the mean of the melatonin control values, a proportion very similar (63\%) to that previously reported (Tordjman et al. 2005). Furthermore, they demonstrate that this deficit was not the consequence of ASD but a primary trait caused by a deficiency in HIOMT activity. Consistent with this primary deficit, parents were found to have lower melatonin than controls. Hence, in one family, the mother and the affected son carried an $A S M T$ splice site mutation, and both have virtually no circadian variation of melatonin level (Fig. 3, bottom right). This anomaly observed in some parents indicated that the melatonin deficit by itself is not sufficient to cause ASD.

Interestingly, one of the most consistent biochemical findings in ASD is the observation of high serotonin levels in affected individuals and their relatives (Cook and Leventhal 1996). Variations within the serotonin transporter SLC6A4 have been suspected to have a role in this anomaly, but this has never been formally proven. Therefore, one attractive hypothesis to explain the high serotonin levels in ASD is that a primary deficit of melatonin synthesis could indirectly lead to an accumulation of the upstream substrates NAS and serotonin (Fig. 3, top). In this context, a single defect within the melatonin synthesis pathway could lead to both low melatonin and high serotonin levels in ASD. This hypothesis reconciles both results, but it raises the critical question of the real nature of the pathological process. Is it high serotonin or low melatonin or the combination of both that increases the risk of having ASD? Moreover, the pathological role of other compounds produced by the HIOMT and/or intermediate metabolites such as NAS cannot be excluded. The putative roles of serotonin on the susceptibility to ASD have been discussed extensively elsewhere (Cook and Leventhal 1996). The next part of this chapter concentrates on the potential roles of melatonin in the susceptibility to ASD.

\section{ATYPICAL SLEEP AND CIRCADIAN RHYTHMS IN AUTISM SPECTRUM DISORDERS}

Melatonin is one of the factors that sets the internal clock to a 24-hour cycle and therefore is crucial for appropriate regulation of the sleep/wake (S/W) cycle. In humans, the developmental course of the S/W cycle consists of three epochs, i.e., development of the circadian $\mathrm{S} / \mathrm{W}$ cycle by 4 months (Fig. 4), decrease of the daytime sleep by 1.5 years, and establishment of the biphasic S/W cycle by 5 years (Segawa 2006). Normal S/W rhythms seem to be crucial for appropriate cognitive development in children. Moreover, sleep is associated with intense 


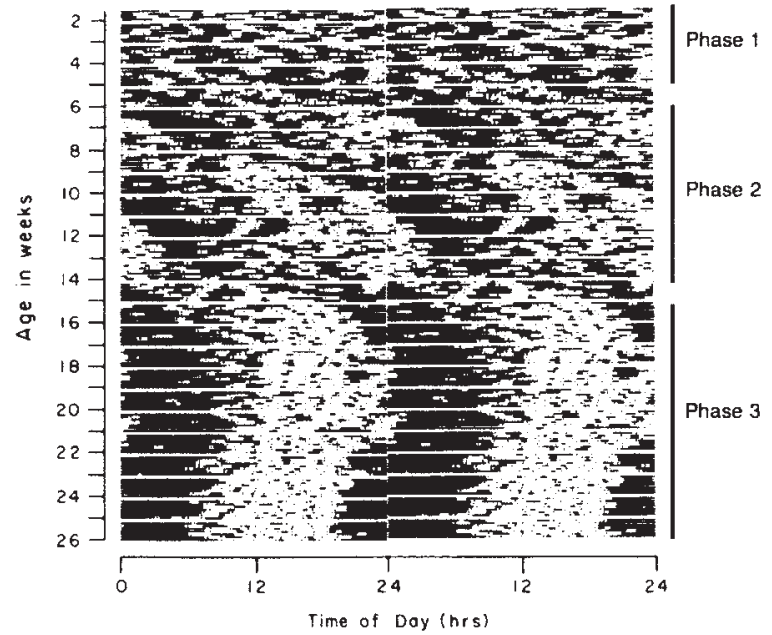

Figure 4. Sleep/wake cycle of a typically developed child during the first 6 months of life. The numbers plotted at the top are 24-hour clock times. Each bar represents 2 days, with the time spent in sleep (black) or awake (white). During phase 1 (from birth until 2 months), the S/W cycle of the child shows no circadian rhythm. In phase 2 (from 2 to 4 months), a free-running pattern is observed. The $\mathrm{S} / \mathrm{W}$ cycle reflects the setting of the internal clock and is out of phase with night and day. In phase 3 , the child has a normal circadian S/W cycle in phase with night and day. (Adapted from Kleitman and Engelmann 1953.)

neuronal function and has an important role on how our memory is formed and ultimately shaped (Stickgold 2005).

Interviews with the parents of patients with ASD revealed that more than $70 \%$ of patients had delayed development of the circadian $\mathrm{S} / \mathrm{W}$ cycle by at least 5 months (Segawa 2006). This problem persists through childhood because $50-80 \%$ of children with ASD show highly significant increased sleep latency and nocturnal awakenings (Richdale and Prior 1995; Taira et al. 1998; Takase et al. 1998; Hering et al. 1999; Elia et al. 2000; Hayashi 2000; Schreck and Mulick 2000; Gail Williams et al. 2004; Wiggs and Stores 2004; Limoges et al. 2005; Oyane and Bjorvatn 2005; Polimeni et al. 2005; Allik et al. 2006; Hare et al. 2006; Liu et al. 2006; Malow et al. 2006). An extensive survey of the sleep problems observed in ASD was recently reported by Liu et al. (2006). In their cohort of 167 children (age $8.8 \pm 4.2,86 \%$ males), $86 \%$ had at least one sleep problem almost everyday, including $54 \%$ with bedtime resistance, $56 \%$ with insomnia, $53 \%$ with parasomnias, $25 \%$ with sleep disordered breathing, $45 \%$ with morning rise problems, and $31 \%$ with daytime sleepiness.

Although sleep problems are repeatedly observed in ASD (predominantly in initiating and maintaining sleep), the occurrence of abnormal sleep patterns, such as fewer rapid eye movement (REM), is still a matter of debate. Some studies could not detect a difference in the sleep architecture of ASD (Tanguay et al. 1976; Elia et al. 2000). Other studies reported increased duration of stage1 sleep, decreased non-REM sleep and slow-wave sleep, fewer stage-2 EEG sleep spindles, and a lower number of rapid eye movements during REM sleep than controls (Diomedi et al. 1999; Daoust et al. 2004; Limoges et al.
2005). This absence of consensus on the sleep architecture in ASD could be due to the difference in the severity of the disorder and in the age of the patients.

Interestingly, when a sleep diary was completed, some individuals with ASD showed a free-running pattern of the S/W rhythm (Fig. 5) (Hayashi 2000; Segawa 2006). Such a pattern is observed in some blind individuals, who cannot perceive the light information of night and day transmitted from the retina to the suprachiasmatic nucleus (SCN) (Skene et al. 1999). Therefore, free-running patterns are highly suggestive of a problem in the circadian setting of the clock. On the basis of this observation, Segawa (2006) postulated that the abnormality in ASD occurs as the child is entering into the day/night cycle. This assumption, made solely on the basis of the sleep pattern, is highly relevant to the melatonin deficit described previously. Therefore, if the anomalies of the $\mathrm{S} / \mathrm{W}$ cycle are caused by a melatonin deficiency, a melatonin treatment should imrove the sleep of the patients.

\section{MELATONIN TREATMENT IN AUTISM SPECTRUM DISORDERS}

Only two small-scale studies have tested the efficacy of melatonin in ASD (Garstang and Wallis 2006; Giannotti et al. 2006). The first study evaluated openly the longterm effectiveness of controlled-release melatonin in 25 children, aged 2.6 to 9.6 years with ASD without other coexistent pathologies (Giannotti et al. 2006). During treatment, sleep patterns of all children improved. After discontinuation, 16 children returned to the pretreatment score; however, readministration of melatonin was again effective. Treatment gains were maintained at 12- and 24month follow-ups. No adverse side effects were reported. In the second study, a randomized, placebo-controlled double-blind crossover trial of melatonin was undertaken in 11 children with ASD (Garstang and Wallis 2006). All sleep parameters (sleep latency, waking per night, total sleep duration) were improved after treatment with melatonin. Hence, both studies provide evidence that melatonin is an effective and well-tolerated treatment for children with ASD and sleep difficulties. However, although sleep was improved, none of these studies could show a significant improvement in cognitive functions and social communication after melatonin treatment. This absence of recovery of cognitive function most likely reflects the presence of other anomalies in the brains of the children with autism. Furthermore, the regulation of the $\mathrm{S} / \mathrm{W}$ cycle in the first years of age may be crucial for this critical phase of development, and therefore, developmental problems may not be reversed by melatonin treatment occurring afterward. For that reason, the early detection of a melatonin deficit in children may greatly improve the efficacy of melatonin treatment in ASD.

\section{WHO CONTROLS WHOM? THE CLOCK OR THE SYNAPSE ?}

The results presented above indicate that at least two pathways are altered in children with autism. One is a synaptic pathway sensitive to gene dosage and has a key 


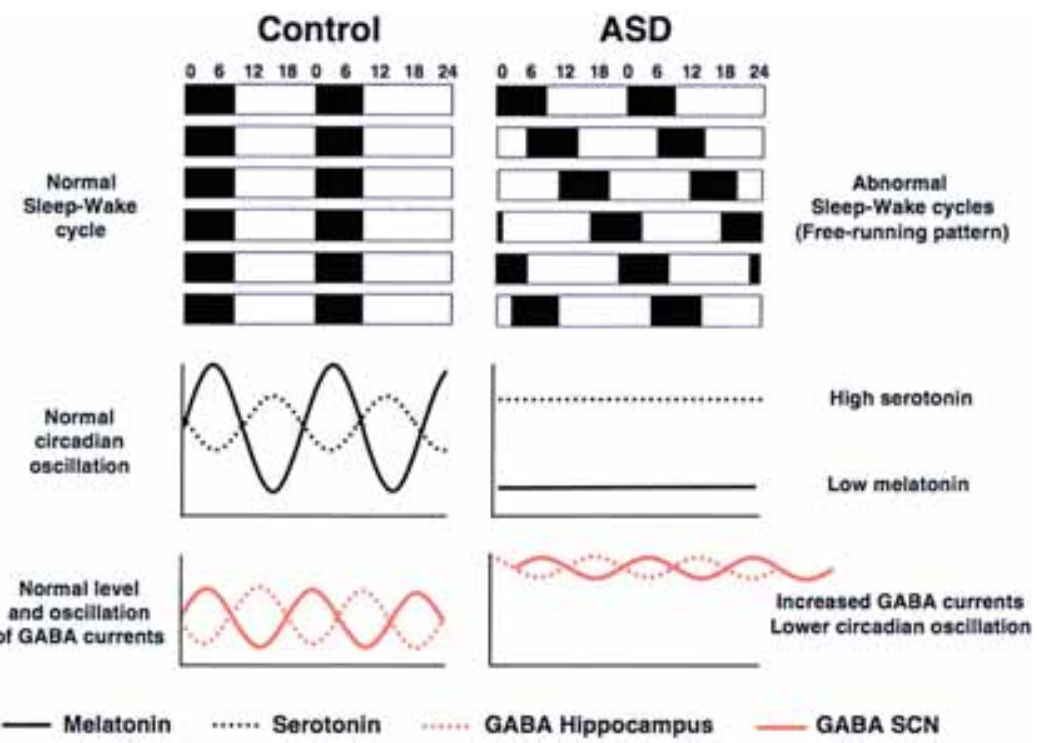

Figure 5. Model of sleep/wake cycles and levels of melatonin, serotonin and GABA currents in a control and a child with ASD. (Upper panel) Schematic diary of a control and an individual with ASD. The numbers plotted at the top are 24-hour clock times. Each bar represents 2 days, with the time spent in sleep (black) or awake (white). Each line is two successive days. The melatonin and serotonin levels are shown below. (Lower panel) Possible circadian oscillation of the GABA currents within the hippocampus and in the SCN. A defect in the NLGN/NRXN/SHANK3 pathway may increase the GABAergic currents and the defect in melatonin synthesis may reduce their oscillations.

role in the establishment of the neuronal network. The second pathway is related to the setting of the clock and is crucial for circadian rhythms of the S/W cycle. Currently, there is no experimental evidence that these pathways interact with each other. However, their critical biological functions strongly suggest that an anomaly in one of these pathways may perturb the other.

Several lines of evidence suggest that melatonin could modulate neuronal networks by influencing both the strength and the circadian oscillation of neuronal transmission (Liu et al. 1997; Jin et al. 2003; Weil et al. 2006). First, melatonin was shown to modulate the phosphorylation of CREB (CRE-binding protein) by decreasing the activity of the cAMP-dependent protein kinase A (PKA) through its binding to melatonin receptor MT1 (von Gall et al. 2000; Jin et al. 2003). Considering the key role of CREB in memory consolidation (Mizuno et al. 2002), the absence of melatonin may alter this process. Second, melatonin significantly inhibits synaptic transmission and long-term potentiation (LTP) in the CA1 region of the hippocampus (Ozcan et al. 2006) through a mechanism involving MT2-receptor-mediated regulation of the PKA pathway (Wang et al. 2005). This inhibition of LTP by melatonin is not mediated by blockade of NMDA receptors (Collins and Davies 1997) or the cholinergic system (Feng et al. 2002) but through the modulation of GABAergic system (Feng et al. 2002).

This emerging role of melatonin in the modulation the GABAergic system (Golombek et al. 1996) may be the most interesting characteristic linking melatonin with the susceptibility to ASD. Indeed, melatonin seems to influence the day/night variations in glutamate and GABA neurotransmitter levels (Marquez de Prado et al. 2000), as well as to modulate GABA-induced currents (Wan et al. 1999; Wu et al. 1999; Prada et al. 2005). Interestingly, melatonin can exert opposite effects: It increases $\mathrm{GABA}_{\mathrm{A}^{-}}$ receptor-mediated current in the rat $\mathrm{SCN}$ via the MT1 subtype, but it inhibits this current in the hippocampus via MT2. In this line, abnormal melatonin levels could reveal a subtle defect in the NRXN/NLGN/SHANK3 pathway that would not have been perceived if GABA oscillations were normal (Figs. 5 and 6).

An alternative possibility is that the NLGN/NRXN/ SHANK3 synaptic pathway could alter the clock and the circadian rhythms in individuals with ASD. Unfortunately, to my knowledge, there is no information on the sleep pattern and circadian rhythms of the patients with mutations within the NLGN/NRXN/SHANK3 synaptic pathway. The same is true for the mice carrying mutations with this synaptic pathway. Nevertheless, mutations in the FMR1 and MECP2 genes were shown to alter the circadian rhythms and $\mathrm{S} / \mathrm{W}$ cycles of patients with Fragile-X or Rett syndrome, respectively. Moreover, Drosophila carrying a mutation in the orthologous gene for FMRI show strong circadian anomalies (Dockendorff et al. 2002). Therefore, the possibility that a defect in the NLGN/ NRXN/SHANK3 synaptic pathway could alter the circadian rhythms in patients with ASD is plausible and further research is warranted to address this issue.

\section{CONCLUSIONS}

Even if genetic and functional data are still sparse, a picture is starting to emerge that at least in some cases, ASD may be due to a problem in the development of specific pathways controlling the wiring of neuronal networks. My hypothesis is that a second anomaly in the setting of the circadian rhythms may reveal, or increase, this synaptic defect in ASD. Many questions remain 


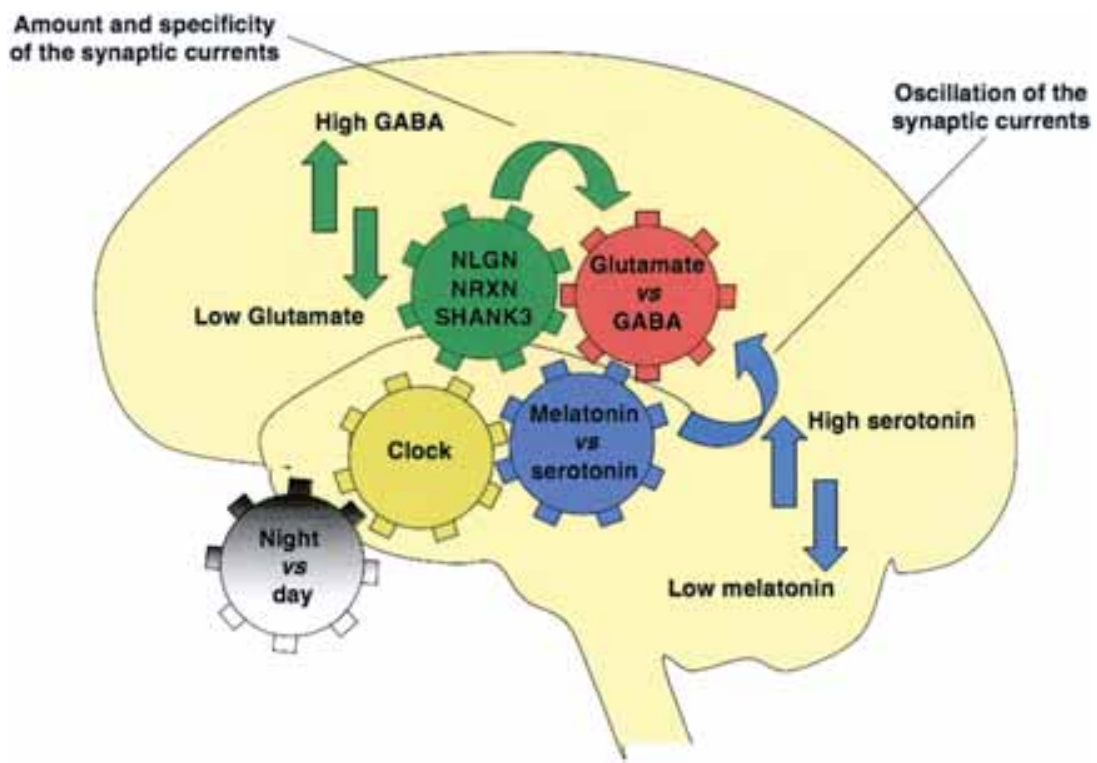

Figure 6. Interplay between the NLGN/NRXN/SHANK3 pathway and melatonin circadian oscillation in ASD. (Cog wheels) Possible interactions between the different pathways. A defect in the NLGN/NRXN/SHANK3 may alter the amount of synaptic contacts as well as the balance between glutamate and GABA. The deficit in melatonin synthesis may alter the oscillation as well as the balance between different synaptic currents (serotonin and GABA). The cumulative effect of both anomalies may greatly increase the risk to have ASD.

unanswered such as the nature of the affected neuronal networks and the potential of reversing the phenotype induced by the mutations. In this line, animal models carrying mutations in the NLGN/NRXN/SHANK3 pathway should provide key information. Recent studies on the mutant mice for Fmrl (Fragile-X syndrome) and Mecp 2 (Rett syndrome) are encouraging because the neurological phenotype could be reversed in mice both by pharmacological treatment (Hayashi et al. 2007) or reactivation of the gene (Guy et al. 2007). On the basis of these lines of evidence, the interactive role between circadian modulation and synaptic function might be one of the most fascinating areas for future functional analyses and for the development of new therapeutic strategies for ASD.

\section{ACKNOWLEDGMENTS}

I thank Moshe Yaniv, Bernard Lakowski, and Ken McElreavey for helpful discussions and comments on the manuscript. This work was supported by the Pasteur Institute, INSERM, Assistance Publique-Hôpitaux de Paris, Fondation France Télécom, Cure Autism Now, Fondation de France, Fondation Biomédicale de la Mairie de Paris, Fondation pour la Recherche Médicale, EUSynapse European Commission FP6, AUTISM MOLGEN European Commission FP6, and ENI-NET European Commission FP6.

\section{REFERENCES}

Allik H., Larsson J.O., and Smedje H. 2006. Sleep patterns of school-age children with Asperger syndrome or high-functioning autism. J. Autism Dev. Disord. 36: 585.

American Psychiatric Association (APA). 1994. Diagnostic and statistical manual of mental disorders, 4 th edition. American Psychiatric Association, Washington, D.C.
Axelrod J. 1974. The pineal gland: A neurochemical transducer. Science 184: 1341.

Bailey A., Le Couteur A., Gottesman I., Bolton P., Simonoff E., Yuzda E., and Rutter M. 1995. Autism as a strongly genetic disorder: Evidence from a British twin study. Psychol. Med. 25: 63.

Barnby G., Abbott A., Sykes N., Morris A., Weeks D.E., Mott R., Lamb J., Bailey A.J., and Monaco A.P. 2005. Candidategene screening and association analysis at the autism-susceptibility locus on chromosome $16 \mathrm{p}$ : Evidence of association at GRIN2A and ABAT. Am. J. Hum. Genet. 76: 950.

Baron-Cohen S., Leslie A.M., and Frith U. 1985. Does the autistic child have a "theory of mind"? Cognition 21: 37.

Belmonte M.K. and Bourgeron T. 2006. Fragile X syndrome and autism at the intersection of genetic and neural networks. Nat. Neurosci. 9: 1221

Blasi F., Bacchelli E., Pesaresi G., Carone S., Bailey A.J., and Maestrini E. 2006. Absence of coding mutations in the Xlinked genes neuroligin 3 and neuroligin 4 in individuals with autism from the IMGSAC collection. Am. J. Med. Genet. B Neuropsychiatr. Genet. 141: 220.

Boeckers T.M., Bockmann J., Kreutz M.R., and Gundelfinger E.D. 2002. ProSAP/Shank proteins - A family of higher order organizing molecules of the postsynaptic density with an emerging role in human neurological disease. J. Neurochem. 81: 903 .

Chih B., Afridi S.K., Clark L., and Scheiffele P. 2004. Disorderassociated mutations lead to functional inactivation of neuroligins. Hum. Mol. Genet. 13: 1471.

Chubykin A.A., Atasoy D., Etherton M.R., Brose N., Kavalali E.T., Gibson J.R., and Sudhof T.C. 2007. Activity-dependent validation of excitatory versus inhibitory synapses by neuroligin-1 versus neuroligin-2. Neuron 54: 919.

Collins D.R. and Davies S.N. 1997. Melatonin blocks the induction of long-term potentiation in an N-methyl-D-aspartate independent manner. Brain Res. 767: 162

Comoletti D., De Jaco A., Jennings L.L., Flynn R.E., Gaietta G., Tsigelny I., Ellisman M.H., and Taylor P. 2004. The Arg451Cys-neuroligin-3 mutation associated with autism reveals a defect in protein processing. J. Neurosci. 24: 4889.

Cook E.H. and Leventhal B.L. 1996. The serotonin system in autism. Curr. Opin. Pediatr. 8: 348

Craig A.M. and Kang Y. 2007. Neurexin-neuroligin signaling in synapse development. Curr. Opin. Neurobiol. 17: 43 . 
Daoust A.M., Limoges E., Bolduc C., Mottron L., and Godbout R. 2004. EEG spectral analysis of wakefulness and REM sleep in high functioning autistic spectrum disorders. Clin. Neurophysiol. 115: 1368.

De Leersnyder H. 2006. Inverted rhythm of melatonin secretion in Smith-Magenis syndrome: From symptoms to treatment. Trends Endocrinol. Metab. 17: 291.

Diomedi M., Curatolo P., Scalise A., Placidi F., Caretto F., and Gigli G.L. 1999. Sleep abnormalities in mentally retarded autistic subjects: Down's syndrome with mental retardation and normal subjects. Brain Dev. 21: 548 .

Dockendorff T.C., Su H.S., McBride S.M., Yang Z., Choi C.H., Siwicki K.K., Sehgal A., and Jongens T.A. 2002. Drosophila lacking dfmr1 activity show defects in circadian output and fail to maintain courtship interest. Neuron 34: 973.

Durand C.M., Betancur C., Boeckers T.M., Bockmann J., Chaste P., Fauchereau F., Nygren G., Rastam M., Gillberg I.C., Anckarsater H., Sponheim E., Goubran-Botros H., Delorme R., Chabane N., Mouren-Simeoni M.C., de Mas P., Bieth E., Roge B., Heron D., Burglen L., Gillberg C., Leboyer M., and Bourgeron T. 2007. Mutations in the gene encoding the synaptic scaffolding protein SHANK3 are associated with autism spectrum disorders. Nat. Genet. 39: 25.

Elia M., Ferri R., Musumeci S.A., Del Gracco S., Bottitta M., Scuderi C., Miano G., Panerai S., Bertrand T., and Grubar J.C. 2000. Sleep in subjects with autistic disorder: A neurophysiological and psychological study. Brain Dev. 22: 88 .

Feng Y., Zhang L.X., and Chao D.M. 2002. Role of melatonin in spatial learning and memory in rats and its mechanism (translation). Sheng Li Xue Bao 54: 65.

Fombonne E. 2005. Epidemiology of autistic disorder and other pervasive developmental disorders. J. Clin. Psychiatry (suppl. 10) $66: 3$.

Freitag CM. 2007. The genetics of autistic disorders and its clinical relevance: A review of the literature. Mol. Psychiatry 12: 2.

Frith U. 1998. Cognitive deficits in developmental disorders. Scand. J. Psychol. 39: 191.

Gail Williams P., Sears L.L., and Allard A. 2004. Sleep problems in children with autism. J. Sleep Res. 13: 265.

Garstang J. and Wallis M. 2006. Randomized controlled trial of melatonin for children with autistic spectrum disorders and sleep problems. Child Care Health Dev. 32: 585.

Giannotti F., Cortesi F., Cerquiglini A., and Bernabei P. 2006. An open-label study of controlled-release melatonin in treatment of sleep disorders in children with autism. J. Autism Dev. Disord. 36: 741

Golombek D.A., Pevet P., and Cardinali D.P. 1996. Melatonin effects on behavior: Possible mediation by the central GABAergic system. Neurosci. Biobehav. Rev. 20: 403.

Graf E.R., Zhang X., Jin S.X., Linhoff M.W., and Craig A.M. 2004. Neurexins induce differentiation of GABA and glutamate postsynaptic specializations via neuroligins. Cell 119: 1013.

Guy J., Gan J., Selfridge J., Cobb S., and Bird A. 2007. Reversal of neurological defects in a mouse model of Rett syndrome. Science 315: 1143.

Hare D.J., Jones S., and Evershed K. 2006. Objective investigation of the sleep-wake cycle in adults with intellectual disabilities and autistic spectrum disorders. J. Intellect. Disabil. Res. 50: 701.

Hayashi E. 2000. Effect of melatonin on sleep-wake rhythm: The sleep diary of an autistic male. Psychiatry Clin. Neurosci. 54: 383 .

Hayashi M.L., Rao B.S., Seo J.S., Choi H.S., Dolan B.M., Cho S.Y., Chattarji S., and Tonegawa S. 2007. Inhibition of p21activated kinase rescues symptoms of fragile $\mathrm{X}$ syndrome in mice. Proc. Natl. Acad. Sci. 104: 11489

Hering E., Epstein R., Elroy S., Iancu D.R., and Zelnik N. 1999. Sleep patterns in autistic children. J. Autism Dev. Disord. 29: 143.

Jacquemont M.L., Sanlaville D., Redon R., Raoul O., CormierDaire V., Lyonnet S., Amiel J., Le Merrer M., Heron D., de Blois M.C., Prieur M., Vekemans M., Carter N.P., Munnich A., Colleaux L., and Philippe A. 2006. Array-based comparative genomic hybridisation identifies high frequency of cryp- tic chromosomal rearrangements in patients with syndromic autism spectrum disorders. J. Med. Genet. 43: 843.

Jamain S., Betancur C., Quach H., Philippe A., Fellous M., Giros B., Gillberg C., Leboyer M., Bourgeron T., and the Paris Autism Research International Sibpair (PARIS) Study. 2002. Linkage and association of the glutamate receptor 6 gene with autism. Mol. Psychiatry 7: 302

Jamain S., Quach H., Betancur C., Rastam M., Colineaux C., Gillberg I.C., Soderstrom H., Giros B., Leboyer M., Gillberg C., Bourgeron T., and the Paris Autism Research International Sibpair Study. 2003. Mutations of the X-linked genes encoding neuroligins NLGN3 and NLGN4 are associated with autism. Nat. Genet. 34: 27.

Jin X., von Gall C., Pieschl R.L., Gribkoff V.K., Stehle J.H., Reppert S.M., and Weaver D.R. 2003. Targeted disruption of the mouse $\operatorname{Mel}(1 \mathrm{~b})$ melatonin receptor. Mol. Cell. Biol. 23: 1054.

Kanner L. 1943 Autistic disturbances of affective contact. Nerv. Child 2: 217 .

Kleitman N. and Engelmann T.G. 1953. Sleep characteristics of infants. J. Appl. Physiol. 6: 269.

Kulman G., Lissoni P., Rovelli F., Roselli M.G., Brivio F., and Sequeri P. 2000. Evidence of pineal endocrine hypofunction in autistic children. Neuroendocrinol. Lett. 21: 31.

Laumonnier F., Bonnet-Brilhault F., Gomot M., Blanc R., David A., Moizard M.P., Raynaud M., Ronce N., Lemonnier E., Calvas P., Laudier B., Chelly J., Fryns J.P., Ropers H.H., Hamel B.C., Andres C., Barthelemy C., Moraine C., and Briault S. 2004. X-linked mental retardation and autism are associated with a mutation in the NLGN4 gene, a member of the neuroligin family. Am. J. Hum. Genet. 74: 552.

Limoges E., Mottron L., Bolduc C., Berthiaume C., and Godbout R. 2005. Atypical sleep architecture and the autism phenotype. Brain 128: 1049.

Liu C., Weaver D.R., Jin X., Shearman L.P., Pieschl R.L., Gribkoff V.K., and Reppert S.M. 1997. Molecular dissection of two distinct actions of melatonin on the suprachiasmatic circadian clock. Neuron 19: 91.

Liu X., Hubbard J.A., Fabes R.A., and Adam J.B. 2006. Sleep disturbances and correlates of children with autism spectrum disorders. Child Psychiatry Hum. Dev. 37: 179.

Malow B.A., Marzec M.L., McGrew S.G., Wang L., Henderson L.M., and Stone W.L. 2006. Characterizing sleep in children with autism spectrum disorders: A multidimensional approach. Sleep 29: 1563.

Manning M.A., Cassidy S.B., Clericuzio C., Cherry A.M., Schwartz S., Hudgins L., Enns G.M., and Hoyme H.E. 2004. Terminal 22q deletion syndrome: A newly recognized cause of speech and language disability in the autism spectrum. Pediatrics 114: 451.

Marquez de Prado B., Castaneda T.R., Galindo A., del Arco A., Segovia G., Reiter R.J., and Mora F. 2000. Melatonin disrupts circadian rhythms of glutamate and GABA in the neostriatum of the aware rat: A microdialysis study. J. Pineal Res. 29: 209.

Melke J., Goubran-Botros H., Chaste P., Betancur C., Nygren G., Anckarsäter H., Rastam M., Ståhlberg O., Gillberg I.C., Delorme R., Chabane N., Mouren-Simeoni M.C., Fauchereau F., Durand C.M., Chevalier F., Drouot X., Collet C., Launay J.M., Leboyer M., Gillberg C., and Bourgeron T. 2007. Abnormal melatonin synthesis in autism spectrum disorders. Mol. Psychiatry (in press).

Meyer G., Varoqueaux F., Neeb A., Oschlies M., and Brose N. 2004. The complexity of PDZ domain-mediated interactions at glutamatergic synapses: A case study on neuroligin. Neuropharmacology 47: 724

Missler M. 2003. Synaptic cell adhesion goes functional. Trends Neurosci. 26: 176.

Mizuno M., Yamada K., Maekawa N., Saito K., Seishima M., and Nabeshima T. 2002. CREB phosphorylation as a molecular marker of memory processing in the hippocampus for spatial learning. Behav. Brain Res. 133: 135.

Nicholas B., Rudrasingham V., Nash S., Kirov G., Owen M.J., and Wimpory D.C. 2007. Association of Per1 and Npas2 with autistic disorder: Support for the clock genes/social timing hypothesis. Mol. Psychiatry 12: 581. 
Nir I., Meir D., Zilber N., Knobler H., Hadjez J., and Lerner Y. 1995. Brief report: Circadian melatonin, thyroid-stimulating hormone, prolactin, and cortisol levels in serum of young adults with autism. J. Autism Dev. Disord. 25: 641.

Oyane N.M. and Bjorvatn B. 2005. Sleep disturbances in adolescents and young adults with autism and Asperger syndrome. Autism 9: 83.

Ozcan M., Yilmaz B., and Carpenter D.O. 2006. Effects of melatonin on synaptic transmission and long-term potentiation in two areas of mouse hippocampus. Brain Res. 1111: 90.

Persico A.M. and Bourgeron T. 2006. Searching for ways out of the autism maze: Genetic, epigenetic and environmental clues. Trends Neurosci. 29: 349.

Polimeni M.A., Richdale A.L., and Francis A.J. 2005. A survey of sleep problems in autism, Asperger's disorder and typically developing children. J. Intellect. Disabil. Res. 49: 260.

Prada C., Udin S.B., Wiechmann A.F., and Zhdanova I.V. 2005. Stimulation of melatonin receptors decreases calcium levels in Xenopus tectal cells by activating GABA(C) receptors. $J$. Neurophysiol. 94: 968.

Prange O., Wong T.P., Gerrow K., Wang Y.T., and El-Husseini A. 2004. A balance between excitatory and inhibitory synapses is controlled by PSD-95 and neuroligin. Proc. Natl. Acad. Sci. 101: 13915.

Richdale A.L. and Prior M.R. 1995. The sleep/wake rhythm in children with autism. Eur. Child Adolesc. Psychiatry 4: 175.

Rivto E.R., Ritvo R., Yuwiler A., Brothers A., Freeman B.J., and Plotkin S. 1993. Elevated daytime melatonin in autism: A pilot study. Eur. Child Adolesc. Psychiatry 2: 75.

Scheiffele P., Fan J., Choih J., Fetter R., and Serafini T. 2000. Neuroligin expressed in nonneuronal cells triggers presynaptic development in contacting axons. Cell 101: 657.

Schreck K.A. and Mulick J.A. 2000. Parental report of sleep problems in children with autism. J. Autism Dev. Disord. 30: 127.

Sebat J., Lakshmi B., Malhotra D., Troge J., Lese-Martin C., Walsh T., Yamrom B., Yoon S., Krasnitz A., Kendall J., Leotta A., Pai D., Zhang R., Lee Y.H., Hicks J., Spence S.J., Lee A.T., Puura K., Lehtimaki T., Ledbetter D., Gregersen P.K., Bregman J., Sutcliffe J.S., Jobanputra V., and Chung W., et al. 2007. Strong association of de novo copy number mutations with autism. Science 316: 445

Segawa M. 2006. Epochs of development of the sleep-wake cycle reflect the modulation of the higher cortical function particular for each epoch. Sleep Biol. Rhythms 4: 4.

Shaywitz S.E., Shaywitz B.A., Fletcher J.M., and Escobar M.D. 1990. Prevalence of reading disability in boys and girls. Results of the Connecticut Longitudinal Study. J. Am. Med. Assoc. 264: 998.

Simonneaux V. and Ribelayga C. 2003. Generation of the melatonin endocrine message in mammals: A review of the complex regulation of melatonin synthesis by norepinephrine, peptides, and other pineal transmitters. Pharmacol. Rev. 55: 325.

Skene D.J., Lockley S.W., and Arendt J. 1999. Melatonin in circadian sleep disorders in the blind. Biol. Signals Recept. 8: 90.

Stickgold R. 2005. Sleep-dependent memory consolidation. Nature 437: 1272

Szatmari P., Paterson A.D., Zwaigenbaum L., Roberts W., Brian J., Liu X.Q., Vincent J.B., Skaug J.L., Thompson A.P., Senman L., Feuk L., Qian C., Bryson S.E., Jones M.B., Marshall C.R., Scherer S.W., Vieland V.J., Bartlett C., Mangin L.V., Goedken R., Segre A., Pericak-Vance M.A.,
Cuccaro M.L., Gilbert J.R., and Wright H.H., et al. (Autism Genome Project Consortium). 2007. Mapping autism risk loci using genetic linkage and chromosomal rearrangements. Nat. Genet. 39: 319.

Taira M., Takase M., and Sasaki H. 1998. Sleep disorder in children with autism. Psychiatry Clin. Neurosci. 52: 182.

Takase M., Taira M., and Sasaki H. 1998. Sleep-wake rhythm of autistic children. Psychiatry Clin. Neurosci. 52: 181.

Talebizadeh Z., Lam D.Y., Theodoro M.F., Bittel D.C., Lushington G.H., and Butler M.G. 2006. Novel splice isoforms for NLGN3 and NLGN4 with possible implications in autism. J. Med. Genet. 43: e21.

Tanguay P.E., Ornitz E.M., Forsythe A.B., and Ritvo E.R. 1976. Rapid eye movement (REM) activity in normal and autistic children during REM sleep. J. Autism Child. Schizophr. 6: 275.

Tordjman S., Anderson G.M., Pichard N., Charbuy H., and Touitou Y. 2005. Nocturnal excretion of 6-sulphatoxymelatonin in children and adolescents with autistic disorder. Biol. Psychiatry 57: 134.

Varoqueaux F., Jamain S., and Brose N. 2004. Neuroligin 2 is exclusively localized to inhibitory synapses. Eur. J. Cell Biol. 83: 449.

Varoqueaux F., Aramuni G., Rawson R.L., Mohrmann R., Missler M., Gottmann K., Zhang W., Sudhof T.C., and Brose N. 2006. Neuroligins determine synapse maturation and function. Neuron 51: 741.

Vincent J.B., Kolozsvari D., Roberts W.S., Bolton P.F., Gurling H.M., and Scherer S.W. 2004. Mutation screening of X-chromosomal neuroligin genes: No mutations in 196 autism probands. Am. J. Med. Genet. B Neuropsychiatr. Genet. 129: 82.

von Gall C., Weaver D.R., Kock M., Korf H.W., and Stehle J.H. 2000. Melatonin limits transcriptional impact of phosphoCREB in the mouse SCN via the Mella receptor. Neuroreport 11: 1803.

Wan Q., Man H.Y., Liu F., Braunton J., Niznik H.B., Pang S.F., Brown G.M., and Wang Y.T. 1999. Differential modulation of GABAA receptor function by Mel1a and Mel1b receptors. Nat. Neurosci. 2: 401.

Wang L.M., Suthana N.A., Chaudhury D., Weaver D.R., and Colwell C.S. 2005. Melatonin inhibits hippocampal long-term potentiation. Eur. J. Neurosci. 22: 2231.

Weil Z.M., Hotchkiss A.K., Gatien M.L., Pieke-Dahl S., and Nelson R.J. 2006. Melatonin receptor (MT1) knockout mice display depression-like behaviors and deficits in sensorimotor gating. Brain Res. Bull. 68: 425.

Wiggs L. and Stores G. 2004. Sleep patterns and sleep disorders in children with autistic spectrum disorders: Insights using parent report and actigraphy. Dev. Med. Child Neurol. 46: 372 .

Wimpory D., Nicholas B., and Nash S. 2002. Social timing, clock genes and autism: A new hypothesis. J. Intellect. Disabil. Res. 46: 352.

Wu F.S., Yang Y.C., and Tsai J.J. 1999. Melatonin potentiates the GABA(A) receptor-mediated current in cultured chick spinal cord neurons. Neurosci. Lett. 260: 177.

Yan J., Oliveira G., Coutinho A., Yang C., Feng J., Katz C., Sram J., Bockholt A., Jones I.R., Craddock N., Cook E.H., Vicente A., and Sommer S.S. 2005. Analysis of the neuroligin 3 and 4 genes in autism and other neuropsychiatric patients. Mol. Psychiatry 10: 329. 


\section{$\overbrace{\text { CSH' }}^{\infty}$ Cold Spring Harbor Symposia SYMPOSIA on Quantitative Biology}

\section{The Possible Interplay of Synaptic and Clock Genes in Autism Spectrum Disorders}

T. Bourgeron

Cold Spring Harb Symp Quant Biol 2007 72: 645-654

Access the most recent version at doi:10.1101/sqb.2007.72.020

References This article cites 86 articles, 10 of which can be accessed free at: http://symposium.cshlp.org/content/72/645.full.html\#ref-list-1

License

Email Alerting

Receive free email alerts when new articles cite this article - sign up in the box at the Service top right corner of the article or click here.

To subscribe to Cold Spring Harbor Symposia on Quantitative Biology go to: http://symposium.cshlp.org/subscriptions

(C) Cold Spring Harbor Laboratory Press 